\title{
DO ATIVISMO SOCIAL À REVITALIZAÇÃO DO SINDICATO DOS METALÚRGICOS DO POLO NAVAL E OFFSHORE DE RIO GRANDE/RS ${ }^{1}$
}

\author{
From social activism to the revitalization of the Rio Grande Naval and Offshore \\ Pole Metallurgists Union
}

D’AVILA, Ana Paula F. ${ }^{2}$

\begin{abstract}
RESUMO
O objetivo deste artigo consiste em reconstituir o processo de revitalização sindical ocorrido entre 2012 e 2017, decorrente da ampliação intensa e veloz da categoria de metalúrgicos no Polo Naval e Offshore de Rio Grande. O referido processo foi marcado por intensas lutas entre trabalhadores e sindicato, devido à existência anterior de um ativismo social por parte dos trabalhadores. A metodologia utilizada consistiu na realização de entrevistas com dirigentes sindicais, trabalhadores, bem como na consulta ao material disponibilizado pelo sindicato e na revisão bibliográfica atinente ao recorte proposto. Por meio da abordagem teórica da construção de classe enquanto um "fazer-se" na experiência compartilhada, acompanhamos os principais momentos da revitalização sindical e os conflitos com sua base, que obliteravam, em parte sua representação legítima em torno do sindicato institucionalizado. Depreendemos que a consciência de classe, nos termos aqui tratados, conciliou-se com o sindicalismo de movimento já no começo da crise do Polo; mesmo assim, esse momento foi importante para a legitimação de pautas em torno do desemprego. Contudo, diante do desmonte da indústria naval, o sindicato viu sua base erodir e, a partir de então, tem atuado com empresas de pequeno porte, as quais garantem um patamar mínimo de experiência adquirida de organização sindical para futuros ou prováveis empreendimentos no município.
\end{abstract}

Palavras-chave: Ativismo social. Revitalização sindical. Polo naval.

\section{ABStRACT}

The purpose of this article is to reconstruct the union revitalization process, which took place between 2012 and 2017, due to the intense and fast expansion of the category of metallurgists in the Naval and Offshore Pole of Rio Grande. This process was marked by intense struggles between workers and the union, due to the previous existence of social activism on the part of workers. The methodology used consisted of conducting interviews with union leaders, workers, consulting the material made available by the union and bibliographic review regarding the proposed outline. Through the theoretical approach of class building as a "making oneself' in the shared experience, we followed the main moments of union revitalization and the conflicts with its base, which partially obliterated its legitimate representation around the institutionalized union. We understand that class consciousness, in the terms discussed here, was reconciled with movement unionism at the beginning of the Polo crisis, even so this moment was important for the legitimization of agendas around unemployment. However, in view of the dismantling of the shipbuilding industry, the union saw its base erode and, since then, it has worked with small companies, which guarantee a minimum level of experience acquired from union organization for future or probable enterprises in the municipality.

Keywords: Social activism. Union revitalization. Polo naval.

${ }^{1}$ O presente trabalho foi realizado com apoio da Coordenação de Aperfeiçoamento de Pessoal de Nível Superior - BRASIL (CAPES) - Código de Financiamento 001. Texto adaptado após apresentação e discussão no 19ํㅡㄹ Congresso Brasileiro de Sociologia em 2019.

2 Realiza Pós-Doutorado em Sociologia pela Universidade Federal de Pelotas (UFPel). Doutora em Sociologia pela Universidade Federal do Paraná (UFPR). E-mail: anapaulasocio10@gmail.com

Trabalho \& Educação | v.30 | n.3 | p.115-131 | set-dez | 2021 


\section{INTRODUÇÃO}

Em 2006 teve início a construção e instalação do Polo Naval e Offshore em Rio Grande, município situado no extremo sul do Rio Grande do Sul. O Polo se insere na política de reativação da indústria naval no Brasil, operacionalizada mediante programas do Governo Federal que investiram na descentralização da referida indústria, antes concentrada no Rio de Janeiro, com vistas à criação de estaleiros de norte a sul do país - incentivada pelo anúncio da descoberta da camada pré-sal ${ }^{3}$ e pela necessidade de reduzir custos com afretamento ${ }^{4}$ de embarcações estrangeiras, assim como pelo interesse de setores empresariais. Além da preocupação com o desenvolvimento da indústria nacional, tal política visava à garantia de geração de postos de trabalho, de emprego e renda não somente para a indústria naval, mas para toda a cadeia produtiva envolvida. Para isso, criou-se o índice de conteúdo local ${ }^{5}$, o qual deveria ser seguido em cada carteira de encomendas dos estaleiros brasileiros.

O Polo Naval, cujo ápice se deu a partir do ano de 2010, ano de sua inauguração oficial, até 2014, esteve em atividade no município de Rio Grande desde 2006 até março de 2019. O empreendimento, organizado em torno de dois estaleiros - Honório Bicalho e Rio Grande -, entrou em crise em meados de 2015, problema que veio a se aprofundar para o setor, principalmente pela mudança de correlação de força política, expressada pelo golpe parlamentar sofrido pela presidente Dilma Rousseff em agosto de 2016.

Levando em consideração o curto período de operação dos estaleiros no município, houve intenso processo de revitalização do movimento sindical. Emprega-se aqui o termo revitalização por se referir a uma forma de ativismo social ligada, em parte, a um sindicalismo de movimento social. E um movimento social só pode ser definido enquanto tal

quando uma luta coletiva obedece aos seguintes princípios: [...] de (i) identidade (uma comunidade mobilizada e animada por um sentimento de pertença), (ii) oposição (a existência de um adversário comum, claramente identificado), (iii) totalidade (com objectivos sociais mais vastos e apoiado por um projecto cultural alternativo) (TOURAINE, 1984; DIBBEN, 2004 apud ESTANQUE, 2009, p. 56).

Para Estanque (2009), historicamente os sindicatos são caracterizados por diversas lógicas de atuação. No caso em tela, observamos o processo de conformação de uma identidade, pautada em torno de um interesse comum dos trabalhadores, relacionada à busca por melhores condições de trabalho e remuneração, em oposição aos empregadores. No caso analisado, o projeto mais amplo e alternativo do sindicato

\footnotetext{
${ }^{3}$ A camada pré-sal, descoberta em 2007, consiste em uma "grande jazida de petróleo localizada abaixo do leito do mar, com volume de aproximadamente 50 bilhões de barris" de óleo leve, isto é, "a matéria prima encontrada na camada présal tem densidade média, baixa acidez e baixo teor de enxofre, sendo mais fácil de refinar e mais valiosa. (...) A camada pré-sal fica localizada em uma área de cerca de $800 \mathrm{~km}$ de extensão por $200 \mathrm{~km}$ de largura, no litoral entre os estados de Santa Catarina e Espírito Santo. A área total da chamada "província do pré-sal" tem cerca de 149 km² e corresponde a cerca de três vezes e meia a área do estado do Rio de Janeiro" (GOMBATA, 2015, s/p).

4 "Um esclarecimento importante deve ser registrado: apesar do forte impacto positivo à retomada da indústria naval brasileira, essas embarcações não constituem propriedade da Petrobras, ou seja, não são ativos patrimoniais" (CAMPOS NETO, 2014, p. 111).

5 Constituiu-se como fator-chave para garantir a produção de plataformas e demais embarcações no Brasil, cuja obrigatoriedade do cumprimento foi estabelecida mediante o Decreto-Lei 4.925/2003. A operacionalização dessa condição ocorreu no âmbito do Programa de Modernização da Indústria Nacional de Petróleo e Gás (PROMINP), o qual fortaleceu a cadeia produtiva do país. O referido Programa apresentou, no ano de 2004, a "Cartilha de Conteúdo Local" instituindo e definindo metodologicamente uma base de cálculo a ser utilizada.
} 
consistia no apoio às políticas de desenvolvimento local, empurrado pelos trabalhadores do Polo, que se organizavam e realizavam o encaminhamento de suas denúncias de diversas formas. A revitalização, portanto, se deve ao processo de retomada do sindicato, seis anos após o pleno funcionamento do Polo, e de sua representação diante da base de trabalhadores.

O sindicato teve não apenas se reorganizar, mas também de lidar com um ativismo social pré-existente e lutar pela conciliação de interesses com o intuito de obter a legitimação diante de sua base ${ }^{6}$.

As relações de trabalho no Polo Naval caracterizavam-se por uma variedade de vínculos de contratação e de tempo de contrato de trabalho; por empresas terceirizadas e até quarteirizadas; por trabalhadores da região, com pouca ou nenhuma experiência no setor; por trabalhadores experientes, oriundos de outras regiões do país. Portanto, em um contexto de individualização das relações de trabalho e de fragilização do emprego. Paradoxalmente, o mercado de trabalho nacional vivia um processo de elevação do salário-mínimo, de redução do desemprego e de acordos coletivos com cláusulas favoráveis aos trabalhadores que, de certa forma, melhoraram as condições materiais dos trabalhadores, assim como suas condições de luta (GALVÃO, 2014).

O objetivo deste artigo consiste em reconstituir o processo de revitalização sindical ocorrido devido à ampliação da categoria de metalúrgicos com o Polo Naval instituído em Rio Grande. Criado no ano de 1979, portanto no âmbito do Novo Sindicalismo, o Sindicato dos Trabalhadores nas Indústrias Metalúrgicas, Mecânicas e de Material Elétrico de Rio Grande (STIMMMERG) contava, até então, com "[...] pouca atividade e quase nenhuma participação nos problemas da categoria" e por isso "foi por muitos anos um Sindicato omisso e sem expressão" (STIMMMERG, 2015)7. Essa pouca dinamicidade também diz respeito ao baixo número de trabalhadores no setor, que após intenso aporte de trabalhadores levou seis anos para começar a atender as demandas. Entretanto, esse processo não foi de modo algum unívoco, uma vez que a revitalização do sindicato foi marcada por disputas em torno da legitimidade de sua representação.

Essa disputa coloca em pauta o caráter pedagógico da ação sindical. Nesse sentido, podemos inferir que se a escola visa à formação de cidadãos e cidadãs, no caso em tela é na luta sindical que se realiza a qualificação política dos cidadãos e das cidadãs. Ou seja, assim como a escola contribui para a formação de valores e atitudes que se traduzem em comportamentos, o engajamento no sindicato proporciona a formação de valores que redundam e influenciam a atuação dos trabalhadores em sociedade. Cabe ressaltar que este ponto perpassa o presente artigo, mas não será aprofundado, pois visamos aqui refletir sobre o eixo trabalho e educação cujo texto consiste em exercício de estabelecer o vínculo.

A metodologia utilizada consistiu na realização de entrevistas com trabalhadores, trabalhadoras e representantes sindicais, bem como em consulta ao material disponibilizado pelo Sindicato, a reportagens referentes ao assunto, entre outros registros. A linha interpretativa que nos auxilia metodologicamente tanto na

\footnotetext{
${ }^{6}$ Tratamos essa questão como ativismo social, pois o sindicato, em um primeiro momento, permaneceu à margem dessas ações.

${ }^{7}$ O STIMMMERG filiou-se à Confederação Nacional dos Metalúrgicos (CNM) da Central Única dos Trabalhadores (CUT) e tem representação intermunicipal. Em outubro de 2018, por ocasião de uma pesquisa feita para a Rede de Estudos e Monitoramento Interdisciplinar da Reforma Trabalhista (REMIR), descobrimos que o sindicato tem em sua base 300 trabalhadores do setor naval e 1.500 de outros setores econômicos. O número de filiados era de 150 trabalhadores.
} 
compreensão quanto na explicação do fenômeno no contexto estudado se baseia na abordagem de Edward P. Thompson (1981; 2017).

Além desta breve introdução, o texto está estruturado em duas partes. Na primeira, articulamos a explicação teórica do referenciado autor, operacionalizando-a metodologicamente, e explicamos o contexto socioeconômico mais amplo do Polo Naval que foi o pano de fundo da conformação de uma experiência compartilhada. Na terceira parte, analisamos a passagem de um ativismo social por parte dos trabalhadores para a legitimação das pautas do sindicato, o que configura, além de um processo de revitalização sindical, a consciência de classe desses trabalhadores e trabalhadoras. Demonstramos ainda o processo que parte da "experiência de classe" até a "consciência de classe" vivenciado pelo sindicato dos metalúrgicos e pelos trabalhadores e, principalmente, o momento dessa articulação, que foi atravessado pela crise e pelo ocaso da indústria naval citadina. Por fim, tecemos algumas considerações que apontam para a importância da revitalização sindical e sua manutenção como patamar mínimo alcançado pela e para a organização dos trabalhadores, a despeito do desmonte do Polo Naval.

\section{DA INSTALAÇÃO AO ÁPICE DO POLO NAVAL: EXPERIÊNCIAS PARTILHADAS}

Em termos legais, o Polo teve seu aval em fevereiro de 2005, com a Lei Municipal $\mathrm{n} .$. 6.058, que instituiu incentivos fiscais para a instalação do estaleiro Rio Grande LTDA. (RIO GRANDE, 2005), por seu turno, a contrapartida do empreendimento era a geração de postos de trabalho.

Em julho do mesmo ano, representantes da Petrobras vieram ao município para analisálo em termos de capacidade para recepção dos investimentos vindouros. Além da expectativa gerada em torno da melhoria dos indicadores socioeconômicos, por conta da criação de postos de trabalho e da consequente dinamização da economia, esperavase uma melhoria da região como um todo. Em relação ao emprego, por exemplo, estimava-se a geração de quarenta mil postos de trabalho diretos e indiretos entre 2005 e 2015.

Tão logo a indústria naval começou a operar no município, com a montagem da plataforma de petróleo P-53, teve início um processo intenso que demandava trabalhadores qualificados. Em um primeiro momento, os próprios estaleiros passaram a qualificar os trabalhadores em "escolinhas" situadas nas próprias instalações. Além disso, o Serviço Nacional de Aprendizagem Industrial (Senai) passou a ofertar cursos no ramo da metalurgia, como o de soldador.

Houve então uma iniciativa do Governo Federal, de âmbito tripartite, envolvendo trabalhadores, empresários e entidades governamentais - o chamado Plano Setorial de Qualificação (Planseq) -, que em setembro de 2011 ofereceu 467 vagas para os cursos de soldador de estruturas metálicas, caldeireiro, maçariqueiro, esmerilhador e soldador de tubulações. Tais cursos tinham duração de 200 horas, começaram em outubro e terminaram em dezembro do referido ano. Eles visavam à qualificação de uma mão de obra inexperiente no ramo da construção naval e ocorriam enquanto a demanda por trabalhadores qualificados era suprida por trabalhadores de outras regiões do Brasil e, ainda, de outros países.

Desse modo, o município gaúcho recebeu, em curto período de tempo, um número significativo de trabalhadores metalúrgicos. Tal aumento exponencial não condizia com 
a realidade da cidade até então, visto que a categoria era composta por um contingente pequeno, com pouca expressão em termos de organização.

[...] é assim a história do sindicato dos metalúrgicos: sempre foi um sindicato pequeno pela história da metalurgia no município, basicamente a gente se baseava em empresa de esquadrias, em serralherias. A gente tinha poucas metalúrgicas e as que tinham não tinham expressão, eram pequenas que abasteciam: 15/20 trabalhadores. Então, não tinham expressão e a expectativa? Eu posso te dizer assim, que não tinha também, porque era tudo muito diferente. Eu te digo, como cidadão, como trabalhador que tive dentro do Polo Naval, a gente não tinha expectativa, não tinha ciência que nós tínhamos o sindicato. A gente tinha ciência que tinha uma pessoa aqui, mas assim nós estávamos preocupados em viver aquele momento, porque a gente também não sabia nada. E viver tudo aquilo ali que para nós era novidade! Então, eu acho que o sindicato lá em 2003, em meados de 2006, não tinha uma relevância expressiva porque a empresa se instalando, se criando todo um movimento dentro do município, que não se falava em sindicato naquela época (Dirigente sindical, Rio Grande, 1.ำ de julho de 2016).

Mesmo com o movimento de contratação gerado pelo Polo Naval e o impulsionamento das atividades e da categoria, paradoxalmente, conforme o relato do dirigente sindical e trabalhador do Polo na época de sua instalação, não havia sequer noção da existência de sindicato nesse período. Entretanto, havia um sindicato que representava os trabalhadores, mas ele tinha pouca tradição e representatividade. Ou seja, legalmente os trabalhadores eram representados pela figura do sindicato, que expressava, a priori, "a condição de cada sindicato vir a ser efetivamente o veículo de identidade dos trabalhadores". Entretanto, esse sindicato não tinha representatividade de fato, que é "um atributo institucional intrínseco ao sindicalismo, embora dependente de conquista", que "integra o constante processo de legitimação/aceitação do sindicato junto aos trabalhadores desde o chão de fábrica, em diferentes níveis". Havia sim uma representação de direito, um sindicato, mas ela não era efetiva no que diz "respeito ao trabalhador se sentir representado pelo sindicato, independentemente de sua filiação", como analisam Bridi, Araújo e Motim (2007, s/p).

Essa ausência de representatividade foi enfrentada pelos trabalhadores, e desde então o sindicato começou a ser revitalizado e reorganizado. Em maio de 2011, os trabalhadores depuseram o antigo presidente do sindicato em virtude de, entre outras questões, ausência de representatividade e abandono da categoria, já que estava em exercício desde 2002 e, portanto, acompanhou todo o movimento de instalação do Polo Naval no município sem se ocupar com a reorganização da categoria.

Durante um breve período, dois representantes escolhidos por alguns trabalhadores concluíram o mandato (Ver Anexo). Em 2012 houve o pleito eleitoral para a escolha da nova diretoria, e o presidente do sindicato foi eleito com $90 \%$ de aceitação, sendo que o número de filiados saltou de 40, em 2011, para 1.500, no ano de 2015. A partir de então, os novos dirigentes precisaram reorganizar o sindicato:

Bom, primeiro eu me deparei com o problema de organizar o sindicato. Porque eu assumi um sindicato, de uma categoria que já teria passado aí cerca de dez, quinze mil trabalhadores e teve arrecadação disso tudo. E quando o ex-presidente some, entrega a carta de demissão, após a pressão que a gente fez, a gente veio a descobrir que o sindicato tinha dívidas (Dirigente sindical, Rio Grande, 4 de abril de 2016).

O mesmo dirigente sindical relata que o Polo vinha gerando uma arrecadação desde 2006, pelo menos, mas o sindicato, além de não representar de fato a categoria, tinha uma série de dívidas: "o próprio alvará de funcionamento do sindicato estava vencido, 
então a gente começou a correr contra isso, melhorando o sistema de pessoal também, porque tudo era errado" (Dirigente sindical, Rio Grande, 4 de abril de 2016). Durante esse processo de regularização das pendências financeiras, o presidente do sindicato contou com o auxílio da Federação dos Metalúrgicos. A partir de então, o sindicato montou o próprio setor de recursos humanos, contratando para isso três trabalhadores graduados em Contabilidade e uma empresa de consultoria para realizar um levantamento geral e averiguar todas as questões pendentes. Feito esse primeiro passo, no sentido de reorganizar jurídica e financeiramente o sindicato, os dirigentes se voltaram para os trabalhadores.

Onde que a gente começou a trabalhar, bom pessoal, primeiro: porta da fábrica! Vamos lá mostrar a nossa cara, esse é o primeiro passo. Mostrar que agora eles têm um lugar para ir, que as portas estão abertas, que eles têm uma casa, que é a casa do trabalhador (Dirigente sindical, Rio Grande, 1.ำ de julho de 2016).

Para os novos dirigentes sindicais, era importante que os trabalhadores soubessem onde poderiam recorrer a seus direitos, que eles tivessem um ponto de referência no horizonte de suas demandas, algo que esses dirigentes - que antes eram trabalhadores do Polo - não tiveram. Todavia, os novos dirigentes encontraram dificuldades, pois em uma das primeiras paralisações na qual se colocaram como representantes dos trabalhadores encontraram resistência, conforme relato a seguir:

Quando a gente chegou lá os caras não nos queriam: "agora é conosco e nós vamos negociar". Não queriam a nossa representatividade, porque era assim $80 \%$ da mão de obra era de fora do estado. E a gente sofreu uma represália muito grande porque o primeiro passo foi nós os dois [presidente e vice] - eles quase viraram o carro: "Não queremos a representatividade de vocês aquil". Eles fecharam lá [Estaleiro], foram três dias de puro caos. E a gente foi lá e entrou para reunião e discutiu, e tudo que eles estavam pedindo estava dentro do acordo coletivo que a gente tinha. Então, mas só que a coisa já estava feita. A nossa representatividade dentro do contexto, a gente tá sempre ali, se tem confusão a gente tá sempre ali, mas como eu te digo assim, sempre priorizando o diálogo antes, sempre, nunca a gente fez assim: vamos parar e depois a gente conversa (Dirigente sindical, Rio Grande, 1.. de julho de 2016).

Como relata o dirigente entrevistado, os trabalhadores experientes e de outros estados não aceitavam o sindicato, situação que pode ser explicada, entre outros motivos, pelas experiências pretéritas de parte dos trabalhadores, que estavam acostumados com a realização de paralisações e com a incapacidade, até então, de o sindicato da categoria representá-los. Ou seja, até então a ação coletiva, fruto de um ativismo social, era a forma pela qual os trabalhadores encaminhavam suas demandas e obtinham a resolução. Isso se revela no próprio argumento do dirigente sindical, o qual elucida que as reivindicações desses trabalhadores já estavam na convenção coletiva, contudo a negociação entre os dirigentes sindicais, a empresa e os trabalhadores tornou-se um pouco mais demorada devido a essa ação mais autônoma e espontânea.

Segundo o dirigente sindical, o estaleiro permaneceu fechado durante onze dias devido à falta de condições de trabalho. Isso se deveu a uma denúncia feita pelo sindicato dos trabalhadores, cujo estopim foi a falta de ventilação dentro do bloco, conforme o seguinte relato:

uma vez que tu começas a soldar, o cara começa a lixar, tu começas a criar gases ali e não tem oxigênio e tem que ter o exaustor para puxar esses gases pesados e têm que ter um mangote de ar pra entrar lá pra dentro, né. E a gente também pediu, na época, bebedores

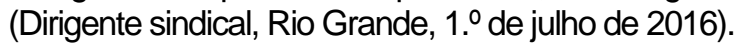


Em outubro de 2012, o STIMMMERG deu um passo importante no processo de revitalização e soerguimento do sindicato, mediante o estabelecimento da Convenção Coletiva de Trabalho (2013/2014), com efeito retroativo para o mês de maio - data-base dos metalúrgicos da região. Nesse documento, constam as diretrizes que asseguravam a trabalhadores e trabalhadoras metalúrgicos o devido respaldo legal, em acordo com o Sindicato Nacional da Indústria da Construção e Reparação Naval e Offshore (SINAVAL), que era o sindicato patronal.

Em dezembro desse mesmo ano, houve uma manifestação composta por funcionários de dez empresas. Dentre suas exigências constavam melhores condições de trabalho, pagamento em dia dos salários e do adicional relacionado à insalubridade. Após essa manifestação, houve a primeira negociação coletiva entre o STIMMMERG e o SINAVAL, com base na Convenção Coletiva recentemente acordada (2013/2014).

Para o dirigente sindical, desde a reorganização do sindicato dos trabalhadores a direção prioriza o diálogo "antes de qualquer manifestação de qualquer atividade em relação à luta, a fazer mobilização, a fazer paralisação, ou trancar ou não trancar sempre se criou um diálogo com a empresa" (Rio Grande, 1. ${ }^{\circ}$ de julho de 2016).

\begin{abstract}
Só que a parte principal está lá fora, que é o que me interessa o que move toda, um prejuízo, uma obra parada naquele montante lá, são milhões, são milhões e não são reais. E aí às vezes chega num consenso, olha vamos pagar amanhã, bom eu vou lá falar com eles. Às vezes não chega, quando não chega num consenso, aí tu vês a mobilização. $E$ por isso que eu digo quando o sindicato toma um interdito, mas por que ele tomou um interdito? Mas nenhum juiz pergunta o que se deu. O sindicato teve sentado sim com a empresa tá, e te digo mais, assim, toda vez que existe uma paralisação grande como já aconteceu, nenhum diretor aqui do sindicato entrou sem levar dois ou três trabalhadores junto, porque a gente preza muito pela transparência, porque daqui a pouco a gente sai lá e diz: ah empresa disse... Mas se a gente não levar um trabalhador (do chão da fábrica) com nós ali para ouvir, para discutir e até debater e a gente tem essa prerrogativa (Dirigente sindical, Rio Grande, 1.을 de julho de 2016).
\end{abstract}

Assim, para o novo grupo que assumiu o sindicato, a negociação se tornou um dos instrumentos importantes de ação. Entretanto, como essa forma de negociação sempre precede a mobilização, ou seja, a greve de trabalhadores, o dirigente sindical critica a ação do judiciário quando este concede à empresa um interdito, por considerar que há um desconhecimento dos passos que foram dados para ajustar uma condução a fim de atender uma demanda dos trabalhadores. Além disso, a presença de um pequeno grupo de trabalhadores, escolhidos aleatoriamente, na mesa de negociação tornou-se uma forma de respaldar a ação do sindicato perante trabalhadores e trabalhadoras.

Em 2013 e 2014, períodos que marcaram o ápice das atividades do Polo e o nível de emprego, o sindicato ganhou maior legitimidade entre sua base, ampliando assim seu poder de barganha, o que refletiu em diversas conquistas para os metalúrgicos e metalúrgicas. Todavia, apesar da tática do sindicato de convidar alguns trabalhadores para participar das mesas de negociação, as manifestações e paralisações de caráter mais autônomo continuaram acontecendo. Assim, observamos momentos nos quais havia uma dupla orientação: de um lado, o sindicato pretendia seguir o procedimento voltado para o diálogo com as empresas responsáveis pelos respectivos estaleiros; de outro, ele tinha de atender as manifestações dos trabalhadores depois da deflagração de uma ação mobilizadora, decorrente de conflitos de diversas ordens no chão da empresa. 
Por exemplo, no final de setembro de 2013, logo após um acidente, houve uma grande paralisação que visou apontar as irregularidades no trabalho. Depois de uma assembleia geral, os trabalhadores decidiram que deflagrariam uma greve em $72 \mathrm{~h}$ caso a empresa não apresentasse propostas de melhoria das condições de trabalho, uma vez que a pauta de reivindicações já havia sido enviada pelo sindicato ao estaleiro há três meses e este ainda não havia respondido. Todavia, dessa vez a greve não foi necessária, dado que as negociações começaram imediatamente. Dos quarenta itens colocados em discussão, $70 \%$ deles foram cumpridos pela entidade patronal. Dentre as questões debatidas estavam

\begin{abstract}
[...] a interrupção dos trabalhos em condições climáticas adversas como chuvas e temporais, a remodelação da tabela níveis para o crescimento salarial do funcionário, acréscimo na quantidade de ônibus que realiza o transporte dos servidores, controle e fiscalização da vinda de operários chineses por salários demasiadamente baixos além de condições mais seguras para trabalhar e outras questões. Entre as principais reivindicações está o controle dos desvios de função. O STIMMMERG acordou a instalação de uma unidade móvel na empresa para fiscalização e debate próximo com os trabalhadores. "Vamos elaborar relatórios constantes informando sobre a realização das atividades incondizentes com cada cargo para que a firma corrija as irregularidades", explicou Gonçalves (DIÁRIO POPULAR, 2013).
\end{abstract}

Inferimos que a partir de 2013 ocorreu uma das primeiras conjunções entre a experiência comum vivenciada pelos trabalhadores e o sindicato, configurando um primeiro movimento que, enquanto relação, ao legitimar a relação com o sindicato, criou uma relação de proximidade da categoria. Contudo, as condições de trabalho e a consciência sobre os problemas no chão do estaleiro e de que somente pela ação coletiva seria possível resolver firmava uma disposição para a ação, como destaca o trabalhador entrevistado:

[...] eu acho que todo mundo tem que participar, defender, tentar ao menos a melhorar. Porque se a gente não lutar, ficar "ah Maria vai com as outras, ah se for eu vou", tem que ir! Sem lutar, ninguém dá nada de graça! Aí pelo menos uma pressão tem que fazer, tentar fazer um movimento se colar, colou. Senão colar, agora a lei não ampara mais nós, recuamos. É o jeito (Nilo8, Encanador, Rio Grande, 6 de abril de 2016).

A fala desse trabalhador enfatiza a participação nas paralisações e a defesa do direito dos trabalhadores. Na época da entrevista, Nilo, que era encanador industrial e tinha vinte anos de experiência no ramo da construção naval, se ressentia das mudanças no amparo legal que fragilizavam tanto as reivindicações quanto os trabalhadores. Nesse sentido, ele era adepto das paralisações, embora sentisse que o poder de barganha havia diminuído.

Já a trabalhadora Amanda, montadora de andaime que trabalhava pela primeira vez na indústria naval, tinha um posicionamento diferente não em relação ao sindicato, mas ao modo de encaminhamento das demandas. Apesar de a trabalhadora relatar ter no sindicato uma proteção legal e um respaldo, ela preferia participar das assembleias, sem envolvimento direto nas paralisações, por considerar a realização de denúncias anônimas ao sindicato uma forma importante de se manifestar e ao mesmo tempo se proteger. Para a entrevistada, o sindicato era importante porque respaldava legalmente as paralisações:

\footnotetext{
${ }^{8}$ Todos os nomes dos entrevistados são fictícios
} 
[...] Ele [o presidente do sindicato] diz: "olha se vocês vão parar eu estou com um papel aqui". Ou não primeiro "preciso pegar uma autorização para que vocês não fiquem desamparados", porque ele vai ser multado, mas ele pode pagar uma multa, mas e os colaboradores? Depois pode ser mandado embora e sem a segurança ali. Então, ele sempre procura fazer esse lado ali para nós (Amanda, montadora de andaime, 22 de janeiro de 2016).

Esses dois relatos acerca da participação em paralisações, em que pesem a experiência de trabalho de cada um, enfatizam a dimensão legal ligada à proteção dos trabalhadores e trabalhadoras. Nilo, devido a sua experiência pregressa em outros estaleiros, sentia que a própria legislação tinha recuado, enquanto Amanda, que vivia sua primeira experiência como trabalhadora respaldada por um sindicato combativo, procurava não participar diretamente das paralisações, embora tivesse depreendido a importância de poder externar os problemas atinentes ao trabalho no Polo. Esses dois relatos nos permitem apreender a construção da consciência de classe enquanto relação que inclui a experiência e as percepções oriundas de diferentes trajetórias de vida que desembocam em uma classe, cuja dimensão só se torna apreensível no seu fazer-se enquanto classe.

O debate sobre o tema da classe no capitalismo remonta aos escritos de Karl Marx e está nos primórdios de suas reflexões, principalmente no Manifesto comunista, na Miséria da filosofia, na Ideologia Alemã e na análise de um caso concreto, conforme depreendemos em o 18 brumário de Luis Bonaparte. Em termos conceituais, contudo, Marx deixou incompleta sua análise em virtude de seu falecimento, quando escrevia o III livro de O capital (LONER, 2001).

Segundo Loner (2001), o tema foi retomado por autores marxistas de correntes variadas. No que concerne ao objetivo do presente texto, no qual nos centramos na experiência local de organização dos trabalhadores no Polo Naval de Rio Grande, apoiamo-nos na abordagem da classe enquanto relação social dinâmica construída pela e na história, na economia, na política e na cultura, conforme proposto por Thompson $(1981 ; 2017)$.

Segundo esse autor, a classe operária é um processo histórico pelo qual é condicionada tanto por "acontecimentos díspares e aparentemente desconectados, tanto na matériaprima da experiência como na consciência" (2017, p. 9). O autor distingue classe como a relação presente entre a experiência e a consciência de classe, e afirma que a classe é resultante dessa relação. E na inserção do processo de produção e por meio das experiências engendradas e concatenadas na produção da cultura, de ideias e da política que a classe emerge enquanto relação.

A experiência comum diz respeito às relações entre os trabalhadores em seus contextos específicos, tendo como base o compartilhamento de uma experiência, em parte, oriunda das relações de produção a que estão submetidos. Desse modo, os trabalhadores organizam e reúnem seus interesses em oposição aos interesses de outro grupo de agentes e, ao fazê-lo, conformam certa identidade.

A forma pela qual essas experiências são organizadas ou "são tratadas em termos culturais: encamadas em tradições, sistemas de valores, ideais e formas institucionais" (lbidem, p. 10) define a consciência de classe. Assim, observamos que para o autor a conformação da classe se dá em um duplo sentido associado, isto é, a experiência é determinada, em certa medida, pelo contexto econômico no qual os trabalhadores se inserem, mas a consciência de classe está no nível da ação, a qual pode surgir em 
diferentes lugares e tempos, podendo adquirir a mesma forma, mas não as mesmas características.

O autor argumenta ainda que a classe é uma relação, e não uma coisa. Nesse sentido, ao falarmos de classe devemos nos deter a um período determinado, aos padrões que o grupo assume, a suas ideias e instituições. Ou seja, é o contexto histórico que propicia esse entendimento por meio de uma perspectiva relacional da classe, conforme elucida o autor:

[...] As formações de classe (argumentei) surgem no cruzamento da determinação e do auto atividade: a classe operária "se fez a si mesma tanto quanto foi feita". Não podemos colocar "classe" aqui e "consciência de classe" ali, como duas entidades separadas uma vindo depois da outra já que ambas devem ser consideradas conjuntamente - a experiência da determinação e o "tratamento" desta de maneiras conscientes. Nem podemos deduzir a classe de uma "seção" estática (já que é um vir-a-ser no tempo), nem como uma função de um modo de produção, já que as formações de classe e a consciência de classe (embora sujeitas a determinadas pressões) se desenvolvem num processo inacabado de relação de luta com outras classes - no tempo (THOMPSON, 1981, p. 121).

Sem a pretensão de realizar aqui uma extensa análise das classes, tema controverso nas Ciências Sociais, mas com o objetivo de interpretar e nomear a experiência dos trabalhadores que se organizaram com o objetivo de melhorar suas condições de trabalho, situamos o processo de revitalização do sindicato dos metalúrgicos enquanto relação. Para tanto nos detemos ao contexto socioeconômico que gerou a necessidade de reorganização do sindicato e, na sequência deste artigo, tratamos da experiência comum dos trabalhadores e das disputas travadas em torno da representação legítima de seu sindicato, enquanto processo de consciência de uma categoria que vai tomando feições de uma classe que, em uma posição subordinada, se organiza para mudar suas condições de vida e trabalho.

\section{DO ATIVISMO SOCIAL À LEGITIMAÇÃO DO SINDICATO: A REVITALIZAÇÃO SINDICAL RESULTANTE DA EXPERIÊNCIA}

No começo de 2014 o sindicato e os trabalhadores demonstravam certo alinhamento entre as estratégias adotadas. Os trabalhadores realizaram uma paralisação em fevereiro do referido ano e, depois de algumas reuniões entre sindicato e empresários, encaminhou-se uma pauta ${ }^{9}$ que girava em torno do cumprimento de cinquenta e três pontos, conforme a ata de reunião sindical (STIMMMERG, 2014). Em parte, essa ação foi previamente preparada, de modo a organizar os anseios dos trabalhadores, e refletia o acúmulo de experiência e o apoio de um amplo contingente de trabalhadores, por volta de 24.000 - que incluía os terceirizados - e 1.500 sócios.

\footnotetext{
${ }^{9} \mathrm{Na}$ pauta reivindicada estavam imbricados interesses de uma parcela significativa do Polo, embora incluísse as demandas dos trabalhadores de um só estaleiro. Além de dispor de um número significativo de trabalhadores, essa pauta continha temas relacionados à contratação, tais como a promoção de nível, a promoção de cargo e o reconhecimento na carteira de trabalho, entre outras, além daquelas atinentes às condições de trabalho, que envolviam desde o revezamento para o horário de almoço até o acesso aos banheiros. Todas as cláusulas eram seguidas de status, e no momento de assinatura quarenta e uma cláusulas contavam como atendidas e dez estavam encaminhadas para resolução até o final de fevereiro de 2014. Por último, mas não menos importante, a última cláusula da negociação versava sobre o não despedimento dos trabalhadores que participaram da reivindicação. Essa última questão era seguida da justificativa do sindicato patronal e da empresa, de acordo com os quais as demissões que porventura ocorressem se deviam ao caráter rotativo da própria atividade, visto que a empresa contava com oito mil trabalhadores na época.
} 
Chamou-nos atenção uma imagem impressa ao final das cláusulas da primeira Convenção Coletiva (2013/2014). Ao mesmo tempo em que ela apresenta os trabalhadores em assembleia durante uma paralisação, ela também revela uma das estratégias do sindicato para obter a legitimação necessária ao enfrentamento dos interesses dos trabalhadores: "existe apenas uma receita para esta vitória, é a da classe somada ao seu sindicato ao contrário quem tem força é o poder patronal some-se ao seu sindicato e descubra como você pode ser maior ainda [...] (STIMMMERG, 2013/2014, p. 50)" - grifos nossos.

Além disso, a legenda dessa imagem sugere que ainda havia separação entre os trabalhadores, designados como classe pelo sindicato, e o próprio sindicato, alertando para a importante união de interesses como forma de enfrentar os patrões. Enquanto processo de constituição, nessa imagem já observamos o sindicato chamando sua base, mesmo que a diferenciando enquanto classe, para a filiação e a ação mediadas pelos dirigentes sindicais.

Já na edição de maio/junho de 2014 do jornal do sindicato, intitulado O metalúrgico, além de uma manchete que tratava da campanha salarial constavam denúncias dos trabalhadores em relação às condições de trabalho, assim como suas conquistas. Entre elas nos chama a atenção para o fato do reconhecimento.

A reportagem enfoca a demissão por justa causa de sete trabalhadores de uma terceirizada do Polo e revela a postura do sindicato, segundo o qual tais demissões não caracterizavam justa causa. A reportagem ainda enfatiza o papel do sindicato junto aos trabalhadores terceirizados de outra cidade, os quais também foram demitidos, mas respaldados legalmente via pagamento de seus direitos. Esses trabalhadores, que estavam sem esperança de obter um resultado justo da negociação, ficaram surpresos com o êxito da negociação do sindicato e entoaram um grito que, além de reconhecer a atuação do sindicato, a legitimava. Ao fim da reportagem, os representantes do sindicato chamam atenção para a importância de os trabalhadores se unirem, frisando que a força do sindicato era oriunda da união com os trabalhadores.

Em maio de 2014 foi deflagrada uma greve envolvendo 10 mil trabalhadores cuja pauta se orientava por melhores condições de trabalho e salário. Após um mês e meio de negociação, foi feito um acordo em assembleia referente a um reajuste de $9,5 \%$ no salário e aumento do vale-alimentação. Depois dessa definição, o sindicato pretendia se dedicar aos problemas entre trabalhadores e empresas. Contudo, diante do avanço da crise no setor naval, a principal pauta unificadora se deteve na manutenção dos empregos no Polo.

Após a demissão de centenas de trabalhadores e sem a perspectiva de novas licitações e, até mesmo, do cumprimento da entrega das plataformas que estavam na carteira de encomendas, uma série de paralisações foram deflagradas. Em junho de $2015^{10}$, destacou-se $o$ ato do presidente do sindicato, o qual permaneceu sete dias amarrado ao portão do Estaleiro Honório Bicalho como forma de protesto. O conflito se deveu à resistência da Petrobras em assinar um acordo sobre os aditivos do contrato da P-75 e da P-77. O consórcio empresarial, contudo, argumentava que sem os aditivos a melhor solução seria enviar as duas plataformas para serem produzidas na China. Depois de

\footnotetext{
10 AMARAL, Julieta. Metalúrgicos 'se amarram' em estaleiro em protesto em Rio Grande. G1/RS, 26 jun. 2015. Disponível em: http://g1.globo.com/rs/rio-grande-do-sul/noticia/2015/06/metalurgicos-seamarram-em-estaleiro-em-protesto-em-rio-grande.html. Acesso em: 26 out. 2021.
} 
uma reunião entre o presidente do sindicato, o então prefeito do município e um representante da Petrobras, ficou estabelecido que as duas plataformas permaneceriam na carteira de encomendas do estaleiro. As contratações estavam previstas para outubro de 2015, mas iniciaram somente em agosto de 2016, em número reduzido e aquém do esperado.

Em setembro de 2015, os trabalhadores do outro Estaleiro (Rio Grande) realizaram uma manifestação durante dois dias consecutivos devido ao "atraso no pagamento de benefícios, rescisões contratuais e salários da quinzena" (RBS TV, 2016) ${ }^{11}$. Durante o protesto, os trabalhadores caminharam por cinco quilômetros até a sede da Justiça do Trabalho com o objetivo de pedir o desbloqueio das contas da empresa, motivo alegado por ela para o atraso nos pagamentos. Ao final desse mesmo ano, o Estaleiro Rio Grande reuniu os trabalhadores no Diálogo Diário de Serviço (DDS) e, segundo o dirigente sindical, o diretor avisou o seguinte:

[...] oh pessoal, a empresa está com dificuldade para quatro mil trabalhadores de todas as camadas, inclusive terceirizadas. A empresa hoje está com dificuldade financeira espero que vocês entendam: nós não vamos ter para pagar o salário, nem o décimo terceiro (Dirigente sindical, Rio Grande, 1.ำ de julho de 2016).

Segundo o dirigente sindical, os trabalhadores ligaram imediatamente para o sindicato, mas

nesse meio tempo se instalou o caos [porque eles pararam primeiro], mas nos chamaram: os trabalhadores e trabalhadoras perguntaram ‘qual é a orientação?' (grifos nossos). A gente está parado aqui e vamos quebrar tudo! (Dirigente sindical, Rio Grande, 1.을 de julho de 2016 - grifos nossos).

Pela primeira vez foi relatado que os trabalhadores pararam e buscaram o sindicato, indagando-o sobre o que fazer diante da situação.

No ano de 2015 os trabalhadores já vinham sofrendo os impactos da crise que se abatia no Polo, momento em que se pôde observar maior conciliação de interesses e de coordenação da ação entre o sindicato e sua base. Em termos conceituais, inferimos que por meio da vivência comum, isto é, das condições de trabalho e dos problemas enfrentados, e diante da crise, houve o reconhecimento dos interesses comuns ao sindicato e aos trabalhadores e a diferenciação em relação aos interesses dos representantes empresariais, por meio da dimensão da experiência.

Esse processo de construção da classe, portanto, articula-se ao próprio sindicato na reativação de seu papel e em seu empenho para obter legitimidade junto a sua base. Cabe ressaltar que tal legitimidade também foi adquirida, em parte, devido a certa disciplinarização em relação aos procedimentos necessários a adotar para a realização de paralisação. Ao ser aceito, isto é, na adoção de seus procedimentos, revela-se, por seu turno, a legitimação da liderança (LONER, 2001).

Em outubro de 2016, diante de um contexto de desemprego e da expectativa de contratação pelo estaleiro Honório Bicalho muito abaixo do esperado, o sindicato realizou uma manifestação que visava não só aos trabalhadores empregados, mas, principalmente, os desempregados. Para os primeiros, o sindicato defendia melhores

$11 \mathrm{Na}$ reportagem, o sindicato dos trabalhadores informou que o bloqueio e atraso nos pagamentos se deveu ao envolvimento da empresa na Operação Greenfield, da Polícia Federal. 
condições de trabalho, e para o segundo, exigia a reinserção desses trabalhadores no Polo.

Diante de um contexto de entrega das plataformas, do avanço da "Operação Lava-Jato" e das desmobilizações de centenas de trabalhadores, as manifestações diminuíram. Em relação à consciência de classe, construída conflituosamente em uma luta constante entre o reconhecimento e a legitimidade do sindicato, observamos que esta chegou a certo nível de conformação de interesses comuns para confrontá-los com o dos estaleiros do Polo Naval. Contudo, mesmo com esse rápido processo, o desmonte da indústria naval já era flagrante na cidade de Rio Grande e também em outros estaleiros brasileiros.

A data que simboliza o desmonte da indústria naval em Rio Grande é 13 de dezembro de 2016 - menos de um mês depois da alteração do índice de conteúdo local de 65\% para $25 \%$ pelo governo de Michel Temer (2016-2018), fator que, somado à mudança do plano de gestão da Petrobras, praticamente desativou de súbito a indústria naval citadina e se espraiou para os demais Polos Navais brasileiros. No referido dia foram demitidos 3.200 trabalhadores diretos do estaleiro Rio Grande e metade da plataforma P-71 ficou no dique-seco do estaleiro - posteriormente, essa plataforma foi vendida como sucata.

Com a ascensão de Michel Temer à presidência da República, uma série de medidas foram tomadas, desde a Reforma Trabalhista, passando pelo congelamento de gastos públicos por vinte anos (Projeto de Emenda Constitucional 95), até a aprovação da terceirização ampla e irrestrita. No que tange ao setor naval, foi preponderante a alteração do índice de conteúdo local, realizada em novembro de 2016. Tornada facultativa a participação de bens e serviços nacionais na fabricação de naviosplataformas e outras embarcações, isso significou na prática a retirada da obrigatoriedade. Além disso, a Petrobras, principal cliente da então indústria naval brasileira, teve sua participação rebaixada para 30\% nas licitações. Essa guinada, oriunda também dos desdobramentos da "Operação Lava-Jato", da crise econômica e política do país e da queda do preço do petróleo na época, resultou na demissão de 3.200 trabalhadores diretos do Estaleiro Rio Grande (ERG) em dezembro de 2016 (D’AVILA; BRIDI, 2017). Já o Estaleiro Honório Bicalho continuou com um contingente pouco expressivo de atividades e de geração de emprego (em torno de trinta trabalhadores diretos e setenta terceirizados), até encerrar suas atividades em março de 2019.

No ano de 2017 houve algumas manifestações por parte dos trabalhadores e de seu sindicato, as quais resultaram em uma audiência com deputados da Assembleia Legislativa do Rio Grande do Sul (ALRS), na Fundação Universidade do Rio Grande (FURG), cujo objetivo era debater o futuro da indústria naval na região. Essa audiência também contou com presidentes de sindicatos dos metalúrgicos de outros estados da federação. A deliberação consistiu na formação de uma bancada gaúcha pelo Polo Naval de Rio Grande, que buscaria apoio nos governos estadual e federal. 
Figura 1- Protesto dos trabalhadores na audiência pública.

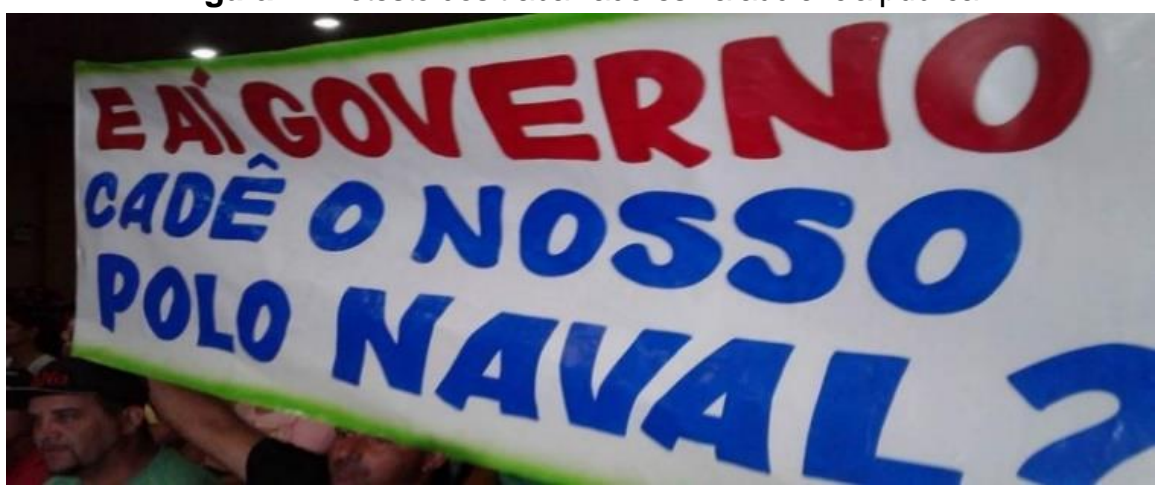

Fonte: STIMMMERG, 2017.

O tema chegou no dia 15 de maio de 2017 à Comissão de Direitos Humanos e à Legislação Participativa (Secretaria de Apoio à Comissão de Direitos Humanos e Legislação Participativa), no Senado, tendo como ponto principal o debate sobre a "Situação dos Polos Navais do Brasil, especialmente do estado do Rio Grande do Sul". Porém, tanto na esfera estadual quanto na federal as tentativas de negociação foram frustradas. Para se ter uma ideia, a Petrobras foi a única que não enviou um representante para participar da discussão.

Desse modo, apenas o Estaleiro Honório Bicalho se manteve em funcionamento, mas com um número muito reduzido de funcionários. Em março de 2018 o estaleiro entregou os módulos da P-75 e da P-77 e não tinha previsão de encomendas em sua carteira. No começo de março de 2018, a Petrobras confirmou que o casco da plataforma P-71 seria feito na China, abandonando assim metade do projeto iniciado no Estaleiro Rio Grande. Em março de 2019, o Estaleiro Honório Bicalho encerrou suas atividades.

Apesar da crise advinda do fechamento do Polo Naval, o sindicato metalúrgico da região vem se reorganizando desde 2016, embora com retração substancial da base. Não se pode negar que os trabalhadores em questão agiram enquanto classe, visto que além de se reconhecerem em oposição ao capital também compartilharam interesses e identidades comuns: trabalhadores metalúrgicos do Polo Naval de Rio Grande, fazendose na história local.

\section{ConsideraçõEs FINAIS}

O ressurgimento da indústria naval ocorreu paralelamente à elevação do padrão de vida da população refletida e foi caracterizado por aumento do salário mínimo, geração de postos de trabalho e emprego, política de desconcentração dos polos de universidades federais para o interior, assim como pela unificação dos institutos federais por meio da criação da Rede Federal de Educação Profissional, Científica e Tecnológica em 2008.

A experiência de sindicalização e de reconhecimento da legitimidade possibilitou a aprendizagem coletiva, pois foi por meio do conflito e do estabelecimento de negociações que se foi conformando a possibilidade de existência de um sindicato enquanto instituição. A reconstrução desse caminho - do movimento sindical para a instituição -, ao revisar seus principais momentos, permite-nos entender como estabelecer um patamar mínimo que possa servir como baliza para experiências futuras.

Neste artigo, revelamos que as duras condições de trabalho no Polo Naval de Rio Grande levaram seus trabalhadores a buscar mudanças por meio do que identificamos 
como ativismo social. Os trabalhadores do chão da empresa costumavam se organizar e responder aos problemas sem o envolvimento direto do sindicato, tanto que o rápido aporte de trabalhadores e trabalhadoras no Polo Naval e Offshore de Rio Grande não foi acompanhado pelo sindicato inicialmente. Entretanto, esse quadro começou a se transformar em 2011, após a deposição do antigo presidente do sindicato dos metalúrgicos, e principalmente com a eleição de uma nova chapa de dirigentes sindicais, oriundos do próprio Polo Naval.

Com base nessa reorganização sindical e na ação coletiva dos trabalhadores ocorreu um duplo movimento, o de revitalização do sindicato, que contava agora com ampla base de trabalhadores, e a luta deste pela obtenção de legitimidade diante dos trabalhadores que representava. Esse processo foi influenciado pela experiência comum partilhada no chão dos estaleiros, mas enquanto tal engendrou oposições, conflitos e ações de deslegitimação na medida em que parte dos trabalhadores desconsiderava os procedimentos indicados pelo sindicato. Essa dificuldade inicial de representação se deveu ao lapso temporal durante o qual os trabalhadores não puderam contar com a entidade sindical, período em que desenvolveram uma experiência de organização e encaminhamento de suas demandas fora do sindicato.

Nesse sentido, foi a dinâmica de um ativismo social e da reorganização sindical assentada na experiência comum que marcou a revitalização sindical dos metalúrgicos de Rio Grande/RS. De acordo com o contexto estudado, houve a conjugação de interesses, ideias e valores em torno do sindicato. Por esse motivo, chamamos o fato de uma consciência em torno da categoria e (por que não?) de uma classe. A revitalização do sindicato, forjada na disputa com a própria base, resultou da consciência que emergiu de uma experiência comum, marcada por dissensos, e é um indicador dessa relação entre o ativismo social dos trabalhadores e a reorganização da entidade sindical.

Depois de dois anos de atividade da nova direção, isto é, em 2014, podemos afirmar que os trabalhadores legitimaram, por meio de um processo de experiência compartilhada, o sindicato enquanto seu representante diante das empresas que comandavam os estaleiros. No breve período de dois anos, observamos a formação de uma consciência que conciliou o ativismo social, visto que passou a haver organização e respeito aos procedimentos indicados pelo sindicato referentes a eventuais paralisações, bem como comunicação ao sindicato e o questionamento sobre o que fazer depois de deflagrado os conflitos.

A ação dos trabalhadores na realidade local pesquisada se deve a certa consciência desenvolvida por eles em relação a seu trabalho, à quantidade de riqueza que produzem e à necessidade de agirem enquanto classe. Essa consciência diz respeito ao conhecimento adquirido no relacionamento com o empregador e a experiências acumuladas nessa relação, possibilitando aos trabalhadores maior clareza quanto a sua situação de classe. É nesse sentido que podemos falar de um "autofazer-se" dos(as) metalúrgicos(as) navais e de seus representantes sindicais.

\section{REFERÊNCIAS}

BRASIL. Decreto no 4.925 de 19 de dezembro de 2003. Institui o Programa de Mobilização da Indústria Nacional de Petróleo e Gás Natural - PROMINP, e dá outras providências. Disponível em: http://www.planalto.gov.br/ccivil_03/decreto/2003/d4925.htm Acesso em: 10 fev. 2017. 
BRIDI, Maria Aparecida; MOTIM, Benilde; M. L.; ARAÚJO, Silvia Maria de. O sindicato e sua representatividade em questão. In: X Encontro Nacional da Abet 2007, Salvador. Anais [...] Salvador: ABET, 2007. v. 1 CD. p. 1-18.

CAMPOS NETO, Carlos Alvares da Silva. Investimentos e financiamentos na indústria naval brasileira 20002013. In: CAMPOS NETO, Carlos Alvares da Silva; POMPERMAYER, Fabiano Mezadre (Ed.). Ressurgimento da Indústria Naval no Brasil (2000-2013). Brasília: IPEA, 2014.

D'AVILA, Ana Paula F.; BRIDI, Maria Aparecida. Indústria naval brasileira e a crise recente: o caso do Polo Naval e Offshore de Rio Grande (RS). Cadernos Metrópole. v. 19, n. 38, jan./abr., p. 249-268, 2017.

DE LA ROCHA, lque. Trabalhadores reconhecem importância do STIMMMERG na defesa de seus interesses. O metalúrgico - Jornal do Sindicato dos Trabalhadores Metalúrgicos de Rio Grande. Rio Grande, maio-jun. 2014.

DE LA ROCHA, lque. Trabalhadores unidos mudaram os rumos do sindicato: A revolução de 2011. Revista do Sindicato dos Trabalhadores nas Indústrias Metalúrgicas, Mecânicas e de Material Elétrico de Rio Grande, ano 1. n. 1, dez. 2015.

DIÁRIO POPULAR. Metalúrgicos do Polo Naval seguem negociação sem necessidade de greve. Diário Popular, Pelotas, 7 out. 2013. Disponível em: https:/www.diariopopular.com.br/geral/metalurgicos-do-polonaval-seguem-negociacao-sem-necessidade-de-greve-74725/?. Acesso em: 24 out. 2021.

ESTANQUE, Elísio. Sindicalismo e movimentos sociais: ação coletiva e regulação social no contexto europeu e português. Lutas Sociais, São Paulo, n. 23, p. 55-67, 2.ํㅗ․ sem. 2009. Disponível em: http://www4.pucsp.br/neils/downloads/05-elisio.pdf. Acesso em: 15 de mar. 2016.

GALVÃO, Andréia. A contribuição do debate sobre a revitalização sindical para a análise do sindicalismo brasileiro. Crítica Marxista, n. 38, p. 103-117, 2014.

GOMBATA, Marsílea. Você sabe como funciona o pré-sal?. Carta Capital. São Paulo, 21 set. 2015. Especiais: infraestrutura, geologia. Disponível em: https://www.cartacapital.com.br/especiais/infraestrutura/voce-sabe-como-funciona-o-pre-sal-8856.html. Acesso em: 21 de maio 2017.

LONER, Beatriz Ana. Construção de classe: operários de Pelotas e Rio Grande (1888-1930). Pelotas: Rede Unitrabalho, 2001.

RBS TV. Operários de estaleiro do RS fazem nova manifestação em Rio Grande. G1, Rio Grande do Sul, 22 set. 2016. Disponível em: http://g1.globo.com/rs/rio-grande-do-sul/noticia/2016/09/operarios-de-estaleirodo-rs-fazem-nova-manifestacao-em-rio-grande.html. Acesso em: 25 set. 2016.

RIO GRANDE. Lei Municipal n. 6.058, de 11 de fevereiro de 2005. Institui o programa de incentivos para operacionalizar a instalação do estaleiro Rio Grande LTDA. Rio Grande: Câmara Municipal, [2005]. Disponível em: https://camara-municipal-de-rio-grande.jusbrasil.com.br/legislacao/520753/lei-6058-05 Acesso em: 16 de mai. 2017.

STIMMMERG - SINDICATO DOS TRABALHADORES NAS INDÚSTRIAS METALÚRGICAS, MECÂNICAS E DE MATERIAL ELÉTRICO DE RIO GRANDE. Ata de reunião para fechamento dos itens acordados na negociação entre Sindicato dos Metalúrgicos de Rio Grande (RS), com o Representante do SINAVAL e Empresa, a partir das reivindicações propostas pelo Sindicato. Acesso ao documento impresso em: 18 de fev. 2014.

STIMMMERG - SINDICATO DOS TRABALHADORES NAS INDÚSTRIAS METALÚRGICAS, MECÂNICAS E DE MATERIAL ELÉTRICO DE RIO GRANDE. Audiência pública em defesa do Polo Naval 13/03 no CIDEC SUL. STIMMMERG, Rio Grande, 2017. Disponível em: http://www.stimmmerg.com.br/index.php?n_sistema=7171\&id_album=NTl=\#ad-image-0. Acesso em: 20 mar. 2017.

STIMMMERG - SINDICATO DOS TRABALHADORES NAS INDÚSTRIAS METALÚRGICAS, MECÂNICAS E DE MATERIAL ELÉTRICO DE RIO GRANDE. Convenção Coletiva de Trabalho 2013/2014.

STIMMMERG - SINDICATO DOS TRABALHADORES NAS INDÚSTRIAS METALÚRGICAS, MECÂNICAS E DE MATERIAL ELÉTRICO DE RIO GRANDE. Sobre o sindicato. Disponível em: http://www.stimmmerg.com.br/index.php?n_sistema=7158. Acesso em: 22 dez. 2015. 
THOMPSON, Edward Palmer. A formação da classe operária inglesa: a árvore da liberdade. Tradução de Denise Bottmann. 8. ed. São Paulo: Paz e Terra, 2017. v. 1.

THOMPSON, Edward Palmer. A miséria da teoria ou um planetário de erros: uma crítica ao pensamento de Althusser. Tradução de Waltensir Dutra. Rio de Janeiro: Zahar, 1981.

TOURAINE, Alain. Le movement ouvrier. Paris: Fayard, 1984.

\section{ANEXO}

\section{Trabalhadores unidos mudaram os rumos do Sindicato A REVOLUÇÃO DE 2011}

O sindicato dos trabalhadores nas Indústrias Metalúrgicas, Mecânicas e de Material Elétrico de Rio Grande surgiu no dia 18 de outubro de 1979. A sede se localizava na rua Conselheiro Anphilóquio Reis, 277. Durante muitos anos, o sindicato foi omisso e sem expressão, sem quase nenhuma participação na defesa da categoria. Em 2010, transferiu sua sede para a rua Dom Pedro I, 628, no bairro Cidade Nova, onde encontra-se atualmente.

A história do STIMMMERG começa a mudar a partir de maio de 2011. Cansados da falta de amparo e do descaso do Sindicato para com seus contribuintes, os trabalhadores da base mobilizaram-se e depuseram do comando da instituição o então presidente, que após 10 anos de mandato tinha conseguido aumentar consideravelmente seu patrimônio pessoal e nunca havia representado sua categoria dignamente. Para conduzir o STIMMMERG no final daquele mandato, os trabalhadores escolheram dois representantes: João Carlos Silva Pereira Júnior, que assumiu a presidência da entidade, e Benito de Oliveira Gonçalves, que ficou responsável pela Tesouraria.

\section{Mudanças em curto espaço de tempo}

Durante essa gestão, que durou pouco mais de 7 meses, e depois de 32 anos caído no esquecimento, o sindicato teve sua sede reformada para atender melhor as necessidades dos colaboradores que procuravam a entidade a todo momento para obter informações e orientações. Houve também a construção do salão social, que não só beneficia os sócios, proporcionando espaço para lazer, como também passou a receber as assembleias e reuniões da categoria.

Em janeiro de 2012 foi eleita a atual diretoria, presidida por Benito Gonçalves, que obteve $90 \%$ de aceitação nas urnas. Em pouco tempo, o sindicato aumentou as vantagens aos associados com a criação de novos convênios, lan house para os sócios e dependentes, obteve área para a construção da sede campestre na Praia do Cassino e prestou contas do primeiro período da gestão, durante um show de prêmios oferecido aos associados. Foi criado o Torneio STIMMMERG de Futebol de Sete e realizadas festas em homenagem aos trabalhadores e familiares. A diretoria implantou o Qualisind, um programa pioneiro de formação profissional, que oferece gratuitamente cursos aos associados e à comunidade, como Instalação de Som, Trava e Alarme Automotivo, Aplicação de Película, Agenciamento Marítimo e Montagem de Andaime. Aqui no sindicato foi formada a primeira montadora de andaimes do Sul do país. E tudo isso foi feito sem perder o foco principal do STIMMMERG: a busca pelo crescimento pessoal e profissional da categoria, melhoria nas condições de trabalho e defesa dos direitos dos trabalhadores.

Com o lema "Trabalho, Ética e Transparência", o STIMMMERG tem provado que é possível fazer uma política sindical limpa e honesta. Com muita luta e graças a essa determinação, temos conquistado ganhos reais a cada ano para a categoria. Só um exemplo: o salário do ajudante, que não chegava a $R \$$ 600 , atingiu em apenas 1,5 ano de nossa diretoria $R \$ 960$. Os últimos reajustes salariais foram os maiores da categoria no país. Como consequência desse trabalho sério, nossos associados saltaram de 40 para 1.500 .

Fonte: extraído e adaptado de: DE LA ROCHA, ano 1. n. 1, p. 6, dez. 2015.

Data da submissão: 29/10/2021

Data da aprovação: 19/02/2021 